\title{
INNOVATIONS
}

\section{Anticipate Ngos' Declare On Intellectual And Real Assault In Tiny Countries}

\author{
Professor. Francesco Abraham, Professor. Mariana Attfield \\ Christian Heritage College, Queensland, Brisbane,Australia
}

\begin{abstract}
Intellectual and real abuses are usually defined because the most misunderstood, common and underreported assaults. Researching facilitate obtain behaviours of those assaults will aid coverage. Our analysis question was whether or not intellectual and real domestic abuse may be expected supported the victim's gender and age and whether or not the victim was living with the suspect(s). Secondary knowledge from the sole out there NGO of assault within the Republic of Cyprus was used. A sample of 590 declareof assault created to the current national helpline was analysed. Binary provision regression was conducted to answer the question of interest. Victims' gender and whether or not or not they were living with the suspect(s) will predict the kind of abuse reportable to alittle extent. Male victims were a lot of seemingly to report intellectual abuse while feminine victims were a lot of seemingly to report real abuse. Victims living with the suspect(s) were a lot of seemingly to report intellectual abuse. No correlation was found between the victims' ages and also the variety of abuse reportable.
\end{abstract}

Keywords: coverage, Cyprus, assault, intellectual abuse, real abuse

\section{Introduction}

Intellectual and real assault are the foremost controversial, misunderstood and troublesome to outline kinds of abuse between members of the family, societies and researchers (e.g. Tolan, Gorman-Smith \& Henry, 2006). Legislation defines intellectual and real assault on general terms however will specify them as crimes once they hurt people (e.g. World Health Organization, 2002). Cyprus law defines intellectual and real assault as a part of the definition of assault quoted as, '...any unlawful act, omission or behaviour which ends within the direct infliction of real, sexual or mental injury to any member of the family by another member of the family...' (Assault within the Family Law, 2004). Intellectual assault typically|is usually|is typically\} redefined as 


\section{INNOVATIONS}

emotional assault and sexual assault is commonly enclosed in real abuse however sometimes is excluded (e.g. Bottoms, et al. 2014). Intellectual abuse and many kinds of real assault, e.g. spanking, may well be thus frequent in family interactions that they're viewed by several as vital parts for the upbringing of kids and elders' care (Shafer, Caetano \& Clark, 1998) and not criminal offences. Inconsistent findings on the results of milder sorts of intellectual and real abuse (Magdol et al, 1997; Margoli \& Gordis, 2000) complicate any these 2 kinds of family assault.

Intellectual and real abuses appear to be the foremost underreported kinds of assault. Iviii p.c of adults World Health Organization intimate intellectual abuse (Foynes, Freyd, \& DePrince, 2009) and between twenty-seven and cardinal p.c of adults World Health Organization intimate real abuse (Foynes, et al. 2009; Hershkowitz, Vladimir Horowitz \& Lamb, 2005; Mazza, Dennerstain \& Ryan, 1996) as youngsters didn't report it to anybody. Bottoms et al, (2014) surveyed one,679 school girls in Chicago to look at reasons for coverage or failing to report childhood abuse. Real abuse was the foremost unreported sort of assault (34 percent). coverage of real abuse was absolutely associated with high frequency of assaults and weak emotional relationships with the wrongdoer. each real and intellectual abuse coverage increased the older the victims were and also the a lot of worry caused to the victim by the abuse. A study within the Netherlands on children's help-seeking behaviours analysed monthly from 1994 to 2008 calls to helplines. The results counsel that children's coverage of assault increased with state and divorce rates (van Dolen, Steven Weinberg \& Ma

The Republic of Cyprus features a population of roughly 838,897 (Statistics Service of the Republic of Cyprus, 2011). Living in such a comparatively tiny country might increase social phobias of coverage assault, e.g. disapproval. Cyprus is repeatedly defined as a paternal society, (e.g. Hadjipavlou, 2010) with male people portrayed a lot of in parliament and also the church as authority figures. Parliament and also the church play an important role in Cyprus' legislation and social norms. The unequal standing of males over females in Cyprus society may be a contributory issue to males being less seemingly to simply accept and report their victimization in incidents of assault. there's one NGO on assault operational in Cyprus and this presents a singular chance to grasp however a rustic declareassault to its NGOs. This study's aim was to grasp however tiny societies report back to NGOs the foremost misunderstood kinds of assault. The analysis question was on whether or not the kind of abuse reportable (intellectual or real) may be expected by analysing victim's gender and/or age and whether or not the victim was living with the suspect(s). 


\section{INNOVATIONS}

As each genders and every one age teams (children, adult and elderly) are equally exploited by intellectual and real abuse, associate equal distribution of coverage these 2 kinds of assault between genders and ages was expected. As this is often the primary study exploring however tiny societies report the 2 most misunderstood kinds of assault once victims reside with the suspect(s), this portrayed associate preliminary approach to the analysis question

\section{Method}

\section{Participants}

The official information of a Cypriot NGO, referred to as SPAVO, was wont to answer the analysis question. The Association for the bar and Handling of Assault within the Family (referred to as SPAVO) is that the solely out there NGO operational within the Republic of Cyprus on assault themes. All SPAVO's services are offered absolve to the general public and embody, a) a national helpline, b) shelters, c) individual guidance conferences with victims and suspects regardless of their age, d) group psychotherapy programs for victims and suspects out there to all or any age teams, e) appearances within the media, schools, conferences and events to tell the general public on assault and f) a recently established analysis team.

\section{Design}

The outcome (dependent) variable was the kind of abuse. There are four sorts of abuse recorded by SPAVO. These are psychological, real, regulatory offense and neglect. staff and volunteers bear in depth coaching on which kind of behaviours may be thought of assault supported Cypriot law. Employees' and volunteers' original selections were used for the study. For the aim of this study, solely intellectual and real abuses were investigated.

There were 3 predictor (independent) variables. First, the victim's gender that was divided into male and feminine. this is often the gender of the victim reportable by the caller and not the caller's gender. The caller may are the victim, a relative or a 3rd party. Second, the victim's age, wherever 3 teams were created, a) youngsters (aged from 0-17 years of age), b) adults (18-60 years older) and c) older (older than sixty one years of age, supported Tobiasz-Adamczyk et al. (2013)). The last variable was whether or not the victim was living with the suspect(s) at the time 


\section{THE AMERICAN JOURNAL OF SOCIAL}

\section{SCIENCE AND EDUCATION}

\section{VOLUME01 ISSUE03}

\section{INNOVATIONS}

of the report that was a divided variable of affirmative (for living with the suspect(s)0 and no (for not living with the suspect(s)).

\section{Results}

Binary provision regression was conducted to predict the kind of abuse (intellectual or real) of 590 cases reportable to SPAVO victimisation the victims' gender (male or female), the victims' cohort (child, adult, elderly) and also the victims' standing of either living with or not living with the suspect(s).

The existence of relationships between the kind of abuse and victims' gender, victims' age and whether or not or not the victims were living with the suspect(s) were supported $(x 2=153.969$, $\mathrm{p}<.001, \mathrm{df}=8)$.

Nagelkerke's R2 of .099 indicated a weak relationship between the kind of abuse and also the 3 freelance variables. The model expected the kind of abuse higher than probability with the classification accuracy rate being overall sixty.5\% (78.1\% for intellectual abuse and forty four.7\% for real abuse).

The Wald criterion incontestible that the victim's gender and whether or not or not they were living with the suspect(s) each created a major contribution to predicting the kind of abuse $(p=$ zero.015 and $p=.002$ respectively). The victim's age wasn't a major predictor $(p=.099)$. $\operatorname{Exp}(B)$ price indicates one.681 for victim's gender and it had been but one for the victim's cohort ( .765) and whether or not or not they were living with the suspect(s) variables (.284).

\section{Discussion}

The present study investigated intellectual and real abuse declarein tiny societies from victims' gender, age and whether or not or not they were living with the suspect(s). The study used an oversized stratified sample and took the distinctive chance to grasp however a rustic declareintellectual and real abuse to its NGO (as SPAVO is that the solely NGO in Cyprus). The 


\section{INNOVATIONS}

study disclosed that the abuse varieties reportable to the NGO were foreseeable to alittle extent however a lot of dependably by the victim's .

The present study adds to the literature on vital gender variations in coverage intellectual and real abuse. Gender variations in coverage assault were additionally documented by earlier studies (e.g. Sarker et al, 2007; Tolan et al, 2005). this study's results indicate that once the victim reportable to the NGO is feminine it's a lot of seemingly that the incident are associated with real abuse. once the victim reportable to the NGO is male it's a lot of seemingly that the abuse can seek advice from intellectual assault. This unequal standing on coverage intellectual and real abuse between the genders may be problematic for preventing and handling assault. The unequal standing of males over females in Cyprus society might have influenced the coverage of their victimization and seeking facilitate. This result shows society's tendency to withdraw male victimization declarebecause of gender difference. This represents society's unbalanced acceptance that if each genders ar equally exploited by these 2 kinds of assault, males will become victims of assault and report it.

Concerning the results of a lot of intellectual assault incidents being reportable once victims reside with the suspect(s), a second policy may be prompt. this is often to target developing a way of trust between organisations (e.g. police and NGOs) and stakeholders (e.g. vital figures). Earlier analysis argues that victims living with suspect(s) might fail to report serious assault incidents (Rodriguez, et al. 2001). Reasons for this vary from victims' fearing lack of support by organizations (Finkelhor \& Wolak, 2003) which coverage might intensify the matter (Andersson, et al. 2010). serving to victims perceive the procedures and support they'd get within the case of coverage is a necessary part to encourage coverage of real assault by victims World Health Organization reside with suspect(s). Lack of data on the procedures followed and support received will lead victims living with the suspect(s) to withhold their accusations.

\section{Conclusions}

It is vital to grasp however individuals report intellectual and real abuse as this constitutes a step towards handling wider challenges close these 2 kinds of family assault. Intellectual and real abuses are the foremost misunderstood, common and underreported assaults. Understanding what affects facilitate seeking attitudes of those assaults will aid coverage. this study indicates 


\section{THE AMERICAN JOURNAL OF SOCIAL}

\section{SCIENCE AND EDUCATION}

VOLUME01 ISSUE03

\section{INNOVATIONS}

that the victims' gender that was mentioned to NGOs will facilitate to predict the abuse kind reportable. Prediction on intellectual and real abuse was additionally authorized to victims' standing of either living with or not living with the suspect(s). Acknowledging gender inequalities in coverage intellectual and real family assault likewise as victims' tendency to suppress coverage of real abuse once living with the suspect(s) shall still puzzle tiny societies. Attention ought to run to cut back any misconceptions associated with genders' victimization in domestic environments and efforts ought to concentrate on developing a way of trust between victims and also the organisations that are committed to support them.

\section{References}

1. Cockcroft, A., Ansari, U., Omer, K., Ansari, N.M., Khan, A., \& Chaudhry, U. (2001). Barriers to revealing and coverage assault among girls, Findings from a national home survey and focus cluster discussion.

2. Holden, G.W. (1995). significant other and real kid abuse: a review and appraisal.

3. Auchter, B. (2008). Men World Health Organization murder their families: What the analysis tells USA. National Institute of Justice Journal.

4. L.C., Epstein, M.A., Wiley, R.A., Reynolds, C.E., \& Rudnicki, A.G. (2004). Abuse characteristics and individual variations associated with revealing childhood sexual, real and emotional abuse.

5. Carrell, S.E., \& Hoekstra, M. (2002). private corporation or social problem? the value of unreported assault.

6. M. M., Freyd, J. J., \& DePrince, A. P. (2010). kid abuse: Betrayal and revelation. illtreatment \& Neglect,.

7. Hadjipavlou, M. (2009). girls and alter in Cyprus: Feminism and Gender in Conflict; I B Tauris \& Co Ltd.

8. Gordis, E.B. (2006). The result of family and community assault on youngsters.

9. Dennerstein, L., \& Ryan, V. (1998). Real, sexual and emotional assault against women: A general practice-based prevalence study. 